\title{
Changes in the diet of predatory ribbonfish Trichiurus lepturus Linnaeus, 1758 with increasing body size along Chennai coast
}

\author{
S. GOMATHY AND E. VIVEKANANDAN \\ Research Centre of ICAR-Central Marine Fisheries Research Institute, 75, Santhome High Road, R. A. puram \\ Chennai - 600 028, Tamil Nadu, India \\ e-mail: gomathycmfri@gmail.com
}

\begin{abstract}
In recent years, it has been recognised that predatory fishes are rapidly declining in marine habitats. Hence, gathering information on biological characteristics such as dietary dynamics of predatory fishes has assumed importance. Considering this, the dietary dynamics of the predatory ribbonfish Trichiuruslepturusfrom Chennai coast was assessed by analysing the stomach condition and contents, with reference to body size. Representatives of the Order Clupeiformes (Index of relative importance, IRI 33.7\%) comprising oilsardine, lesser sardines and anchovies were the major prey items of T. lepturus. Predation by $T$. lepturus was aided by morphological adaptations, such as dentition, hard and spinous gill rakers, short stomach, high body depth-total length ratio of 1: 17.1 and large mouth (gape area of $1534 \mathrm{~mm}^{2}$ in adult fish). With increasing body size, the capacity to predate upon relatively larger prey increased. The differences in diet composition between ribbonfish of small, medium and large size were well-represented byIRI, prey specific abundance and cluster analysis. The fish is a top predator (trophic level: 4.17) and a specialist feeder (niche breadth: 2.63). As specialist feeders have a narrow choice of food, they are more vulnerable to fishing. It is important that management of multispecies fisheries should focus more on the sensitive predatory species.
\end{abstract}

Keywords: Index of relative importance, Morphological adaptations, Specialist feeder, Trichiurus lepturus, Trophic level

\section{Introduction}

The largehead ribbonfish, Trichiurus lepturus Linnaeus, 1758 (Family: Trichiuridae) is a commercially important species, which is landed regularly by trawlers and gillnetters along Chennai coast (south-east coast of India). At Chennai Fisheries Harbour, the trawlers landed $1948 \mathrm{t}$ of ribbonfish, which contributed $6.6 \%$ to the total trawl catch in the year 2015 [data collected from the records available at Madras Research Centre of ICAR-Central Marine Fisheries Research Institute (ICAR-CMFRI)]. Several publications are available on the diet of ribbonfish (Pillai, 1974), but, only a few detail the quantitative diet composition (James, 1967; Ghosh et al., 2014). These earlier studies reported that all species of ribbonfishes are highly carnivorous, predominantly piscivorous and occasionally cannibalistic. The trophic level of ribbonfishes is high at 4.20 and hence, they are grouped as top predators (Vivekanandan et al., 2009). As higher proportion of large predators like the ribbonfishes are removed by fishing, the mean trophic level in the fishery has reduced over the years along the Indian coast (Vivekanandan et al., 2005). This process, called 'fishing down the food web', renders large predatory fishes relatively more vulnerable to fishing, which emphasises the need for gathering exhaustive information on their biology. In this context, information on feeding biology and diet composition will enable adoption of better management strategies on a holistic platform.

Dietary change is a function of changing activity, food requirements and intraspecific competition with age and body size (Holbrook and Schmitt, 1984; Clements and Choat, 1993). Change in diet is an adaptation to avoid competition between young ones and adults. From an ecological perspective, this means that individuals of the same species at different life stages can be functionally separate as different species (McCormick, 1998). With age and increasing body size, the physical structures related to feeding, for example, mouth gape, length of alimentary tract and body shape, change (Kapoor et al., 1975). These changes determine the relationship between the predator and the types and size of prey. Accompanying these changes, the fish often undergo major shifts in trophic level and niche breadth. In some species, the diet shifts dramatically from one trophic level to another. For example, with growth, the diet of the sparid, Diplodus capensis shifts from algae to bivalves (Richardson et al., 2011). This change in diet corresponds to the mouth gape dimensions of the predator. In some other species, the change is limited to the same prey, but of different body size. For example, the predatory 
lizardfish Saurida undosquamis, when young, predates on small-sized clupeids and as adult, it prefers larger sizes of the same prey (Gomathy, 2013). Hence, understanding dietary changes is a prerequisite to assess intraspecific competition. However, these types of studies are not common for tropical fish species.

With the objectives of generating information on the attributes of trophodynamics such as morphological adaptation and changes in the diet composition of predatory fishes in relation to body size, the quantitative and qualitative diet composition of T. lepturus was studied and the results presented here include information on the index of relative importance of prey, trophic level and niche breadth of this fish.

\section{Material and methods}

Fresh samples of T. lepturus were collected weekly from the landings at Chennai Fisheries Harbour from January 2007 to December 2008. The samples were washed and analysed in the laboratory at the Madras Research Centre of ICAR-CMFRI. The total length (TL) of all specimens was measured using a measuring board, to the nearest $\mathrm{mm}$ from the tip of the snout to the tip of the caudal fin. The weight of each fish was determined using an electronic balance (Make: Mira, Sartorius Mechatronics India; accuracy: $1 \mathrm{~g}$ ) after blotting the whole fish to remove the adhering water. The TL and body weight of the sampled fish ranged from 219 to $1200 \mathrm{~mm}$ and 5 to $980 \mathrm{~g}$, respectively.

Upper and lower jaw lengths were measured and dentition pattern and teeth count were recorded (Fig. 1a). Mouth gape area (MGA) was measured (Fig. 1b) employing the formula used for elliptical shape (Ward-Campbell et al., 2005).

Gill rakers on the first gill arch were counted using magnifying electrical hand lens. Stomach length

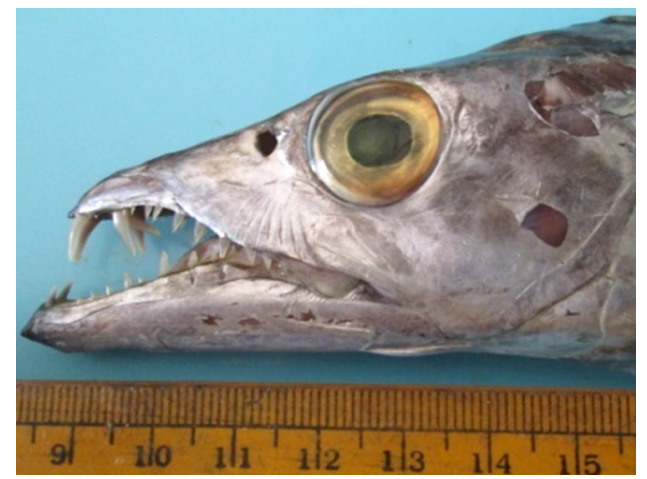

(a) was measured and relative stomach length (RSL) was calculated following Ribble and Smith (1983)

$$
\mathrm{RSL}=\text { Stomach length / Fish total length }
$$

For measuring the stomach, the combined length of foregut, midgut and hindgut were considered. No separate measurement was taken for the intestine as the hind gut was very short (length $<10 \mathrm{~mm}$ ). Within the sample, the data on the length of empty $(n=254)$ as well as full and gorged $(n=41)$ stomachs (SL) were segregated.

Stomach distension was determined by finding out the difference between the length of full, gorged and empty stomach.

Stomach distension $=\frac{(\text { Length of full and gorged stomach-Length of empty stomach })}{\text { Length of empty stomach }} \times 100$

Stomach Condition Index was determined by allotting points to stomach condition from empty to gorged (Pillay, 1952). The following points were allotted based on fullness of stomach: Empty: 1, Trace: 2, Quarter-full: 3, Half-full: 4, three-quarter full: 5, Full: 6, Gorged: 7. The percentage occurrence of each stomach condition in the sample was multiplied with the allotted points and averaged to arrive at stomach condition index (SCI).

Detailed quantitative and qualitative analysis of stomach contents upto the possible identifiable level (family or genus or species) was done. The larger prey were counted visually and small prey using a microscope. Before measuring the weight, the preys were blotted to remove adhering water and mucus. Each prey item was weighed using an electronic balance (Type AW 220, Shimadzu Corporation, Japan, accuracy: $0.1 \mathrm{mg}$ for small prey; Adair Dutt Instruments, accuracy: $0.01 \mathrm{~g}$ for large prey).

Index of relative importance (IRI) of each ingested prey type was estimated as a linear combination of its frequency of occurrence (O), abundance (A) and biomass (B) following Pinkas et al. (1971):

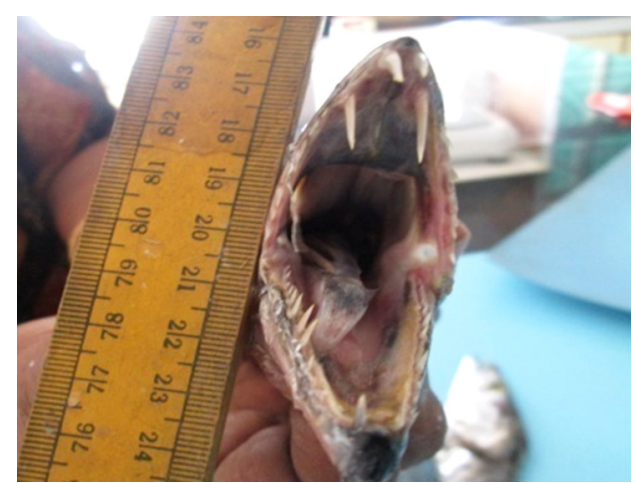

(b)

Fig. 1. Head of T. lepturus (a) Side view of head showing upper and lower jaws and dentition; (b) Fully open mouth facilitating measurement of mouth height and width for determining mouth gape area 


$$
\mathrm{IRI}=(\% \mathrm{Ni}+\% \mathrm{Wi}) * \% \mathrm{Oi}
$$

where $\mathrm{Ni}, \mathrm{Wi}$ and $\mathrm{Oi}$ represent percentages of number, weight and frequency of occurrence of the $i^{\text {th }}$ prey, respectively.

The IRI estimation followed in the present study is a modified version. While percentage of prey volume was used in the original equation, volume was replaced by $\%$ weight of prey in the present study following Alonso et al. (2000). Following Cortes (1997), the IRI is expressed on a percent basis (\%IRI) and for graphical representation as natural logarithm (Ln) of \% IRI. The prey which were in partially digested condition and could not be identified, were categorised as semi-digested and the content that was in liquid form was categorised as digested matter.

Prey specific abundance (PSA), defined as the proportion of numerical abundance of a prey item ' $\mathrm{i}$ ' in relation to the abundance of all prey items in only the predators that contain that particular prey (Amundsen et al., 1996), was calculated using the equation:

$$
\mathrm{Pi}=\left(\sum \mathrm{Si} / \sum \mathrm{Sti}\right) 100
$$

where $\mathrm{P}_{\mathrm{i}}=$ PSA of prey $\mathrm{i} ; \mathrm{S}_{\mathrm{i}}=$ Abundance of prey in stomachs and $\mathrm{S}_{\mathrm{ti}}=$ Total abundance of prey in predators that contain prey $\mathrm{i}$.

PSA, when plotted against frequency of occurrence, can be used to evaluate the three important aspects of fish diet, namely, (i) feeding strategy (specialised vs general), (ii) prey importance (dominant vs rare) and (iii) niche width (Amundsen et al., 1996).

Levins measure of niche breadth (B) and standardised measure of niche breadth (BA) (Levins, 1968) were calculated using the equations:

$$
\mathrm{B}=\frac{1}{\mathrm{P}(\mathrm{ij} 2)}
$$

where $\mathrm{P}_{\mathrm{ij}}=$ Proportion of resource $\mathrm{j}$ used by size class $\mathrm{i}$. The index ranges from 0 (highly specialised) in which only a single prey is used to $\mathrm{n}$ (highly generalised), where $\mathrm{n}$ is the total number of prey types.

$$
\mathrm{BA}=\frac{\mathrm{B}-1}{\mathrm{~N}-1}
$$

where, $\mathrm{B}$ is Levin's niche breadth and $\mathrm{N}$ is the number of prey types. BA values range from 0 to 1 ; values near 0 indicate specialist feeder and those near 1 indicate generalist feeder.

These measures indicate the feeding strategy, i.e, whether the fish is a generalist feeder (with more prey types) or specialist feeder (few prey types). These measures also indicate the possible dietary overlap.
Trophic level (TrL) was calculated from, (a) percent contribution of biomass of each prey type to the total prey biomass in the stomach and (b) trophic level of the prey species (Froese and Pauly, 2000).

$\operatorname{TrL}=\sum$ (WiTi) +1 where $\mathrm{W}_{\mathrm{i}}$ is the percentage by weight contribution of $i^{\text {th }}$ prey item and $T_{i}$ is the trophic level of the $i^{\text {th }}$ prey item. Trophic level of prey types was collected from Fish Base (www.fishbase.org).

All the trophic attributes were analysed by grouping the samples into $10 \mathrm{~mm}$ length groups. For further analysis, the fishes were grouped as small (210-499 mm TL), medium (500-799 mm TL) and large (800-1209 mm TL) length groups. To find out diet similarity, the data were subjected to cluster analysis using PRIMER software (Clarke and Gorley, 2006). Statistical analyses such as standard deviation (SD), regression, correlation coefficient $\left(\mathrm{r}^{2}\right)$ and Student's $\mathrm{t}$ test were performed following Snedecor and Cochran (1967).

\section{Results}

\section{Trophic morphology}

Mouth gape area: The mouth of T. lepturus is elliptical in shape when fully open, with the mouth height measuring 1.4 times the mouth width. For a fish of $800 \mathrm{~mm}$ TL, the mouth height and width are 49 and $34 \mathrm{~mm}$, respectively and the mouth gape area was determined as $1534.4 \mathrm{~mm}^{2}$. The mouth gape area increased linearly with the length of the fish, as given in the regression equation:

Mouth gape area $\left(\mathrm{mm}^{2}\right)=(6.1956 *$ Fish L $(\mathrm{mm}))-3423.1\left(\mathrm{r}^{2}=0.915 ; \mathrm{n}=50\right)$

Maximum body depth (MBD): The body of T. lepturus is laterally compressed, very long and ribbon-like with a tapering tail. The maximum body depth (MBD) of T. lepturus is at the location of beginning of first dorsal fin. For a fish of $800 \mathrm{~mm}$ length, the MBD was $47 \mathrm{~mm}$. The MBD also increased linearly with increasing fish length. The MBD-fish total length ratio was 1: 17.1 and the regression analysis showed the following relationship. Maximum body depth $(\mathrm{mm})=(0.1112 *$ Fish L $(\mathrm{mm}))-39.575$ $\left(\mathrm{r}^{2}=0.8351 ; \mathrm{n}=50\right)$.

Gill rakers: T. lepturus has small, hard and spinescent gill rakers. The first gill arch had 13 gill rakers in each limb. The long $(1.5 \mathrm{~mm})$ and short $(0.5 \mathrm{~mm})$ gill rakers are alternately placed and moderately spaced with a distance of $1.5 \mathrm{~mm}$ between each raker. For a fish measuring $800 \mathrm{~mm}$ total length, the lengths of upper and lower gill arch were $26 \mathrm{~mm}$ and $60 \mathrm{~mm}$ respectively. The $60 \mathrm{~mm}$ long lower gill arch had gill rakers only up to $20 \mathrm{~mm}$ distance and the remaining $40 \mathrm{~mm}$ towards the end was smooth without any gillraker (Fig. 2). 


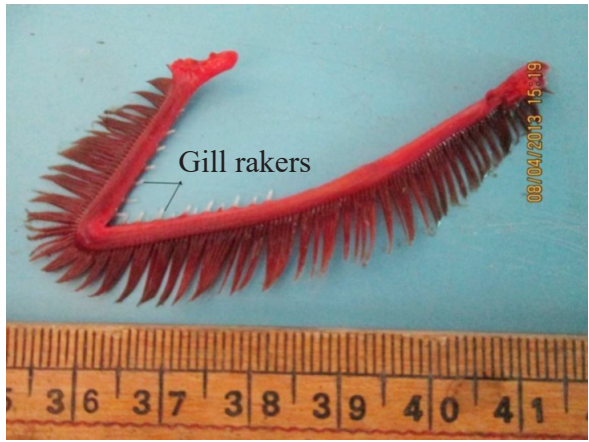

Fig. 2. Structure of first gill arch of T. lepturus

Stomach: The stomach of T. lepturus is a straight, white, slightly muscular and tubular structure with a very short intestine which opens outside by anus. The slightly muscular stomach is very flexible and distends enough to a skinny layer to hold large prey. The length of stomach indicates the volume/size of prey the predator can hold. The relationships between fish length and length of stomach in empty as well as full and gorged stomach conditions were linear.

In empty SL $(\mathrm{mm})=(1.0003 * \ln$ Fish L $(\mathrm{mm}))-1.4142\left(\mathrm{r}^{2}=0.6774\right.$; $\mathrm{n}=254)$

In full and gorged SL $(\mathrm{mm})=(1.0672 * \ln$ Fish L $(\mathrm{mm}))-1.7321$ $\left(\mathrm{r}^{2}=0.8615 ; \mathrm{n}=41\right)$

The calculated stomach lengths using these relationships, for fish of different TL and the estimated stomach distension are presented in Table 1.

\section{Feeding intensity}

With increase in fish size, a decrease in percentage of empty stomach (58.0 to $43.8 \%)$ and increase in percentage of full and gorged stomach (1.5 to 6.3\%) was noticed (Table 2). The condition index (CI) for the large size group was considerably higher $(52.8 \pm 5.9)$ than the other two size groups (CI: 15.0 - 16.0) (Fig. 3).

Table 1. Stomach distension of T. lepturus

\begin{tabular}{llll}
\hline $\begin{array}{l}\text { Fish length } \\
(\mathrm{mm})\end{array}$ & \multicolumn{3}{c}{ Stomach length $(\mathrm{mm})$} \\
\cline { 2 - 4 } & Empty & Full and gorged & $\begin{array}{l}\text { Stomach } \\
\text { distension }(\%)\end{array}$ \\
\hline 250 & 60.8 & 64.0 & 5.3 \\
500 & 121.2 & 133.6 & 10.2 \\
1000 & 242.8 & 282.1 & 16.2 \\
\hline
\end{tabular}

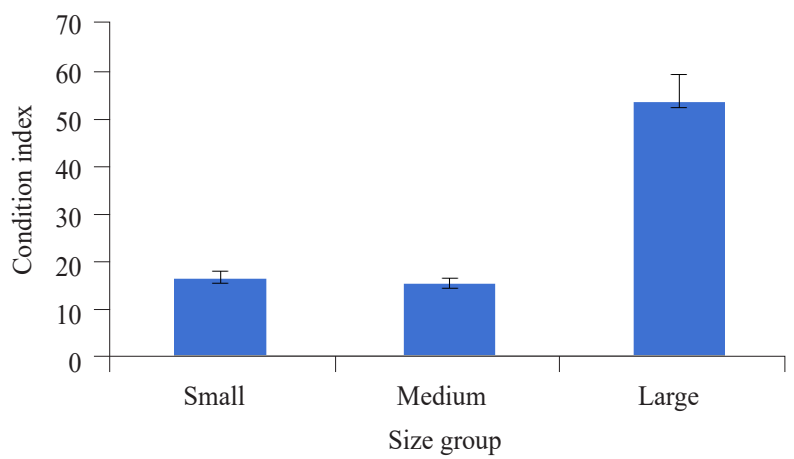

Fig. 3. Condition index of T. lepturus $(\mathrm{n}=878)$, for three size groups; thin vertical lines indicate standard deviation

\section{Prey types}

The food of T. lepturus comprised a variety of prey items. The prey belonged to several orders of teleosts (6), decapods (2) and cephalopods (3), together forming 11 prey groups (orders), 31 genera and 40 species (Table 3 ). Sardines and anchovies (Order Clupeiformes), carangids, goatfish and silverbellies (Order Perciformes) and unicorn cod (Order Gadiformes) were regularly observed in the stomach of T. lepturus. Cannibalism was noticed, but only in $1 \%$ of total samples analysed.

\section{Index of relative importance (IRI)}

Index of relative importance (IRI \%) was estimated for fourteen prey groups, in 380 stomachs (Table 4). Clupeiformes $(33.7 \%)$ dominated the prey groups and was abundant numerically (113), as well as in terms of biomass, contributing $47.3 \%$ to the total prey biomass. Teleosts contributed $94.4 \%$ to the total prey biomass followed distantly by decapods $(3.0 \%)$.

Being the most dominant prey in terms of frequency of occurrence, abundance and biomass, the IRI of Clupeiformes was considerably higher than all other identified groups (Fig. 4a). The Ln\% IRI was high for semi-digested fish, Clupeiformes, decapods and Perciformes. The relative importance of Clupeiformes was high in all size groups (Fig. 4b, c and d). The major difference between small and large size groups was that the decapods were important prey for the small size but were totally absent in the large size groups. Perciformes and Mugiliformes, which were not important prey types for small groups, were highly important for the large size group. Fig. 4b, c and d indicate that as the fish attained

Table 2. Stomach condition of T. lepturus $(\mathrm{n}=878)$; the values are $\%$ of respective category

\begin{tabular}{lllllll}
\hline Category & Fish size $(\mathrm{mm})$ & Empty & Trace and $1 / 4$ full & $1 / 2$ full & $3 / 4$ full & Full and gorged \\
\hline Small & $210-499$ & 58.0 & 19.7 & 17.4 & 3.4 & 1.5 \\
Medium & $500-799$ & 55.7 & 20.0 & 16.2 & 3.8 & 4.3 \\
Large & $800-1209$ & 43.8 & 24.8 & 18.8 & 6.3 & 6.3 \\
\hline
\end{tabular}


Table 3. Prey consumed by T. lepturus

\begin{tabular}{ll}
\hline Order & Genus / species/ common names \\
\hline Anguilliformes & Elver of eels \\
Clupeiformes & Ophisthopterus tardoore, Sardinella gibbosa, \\
& S. longiceps \\
& Stolephorus indicus, S. commersoni, \\
& S. bataviensis \\
& Thryssa setirostris, T. dussumieri and T. mystax \\
Gadiformes & Bregmaceros mcclellandi \\
Mugiliformes & Mugil cephalus \\
Myctophiformes & Myctophids \\
Perciformes & Acanthocepola indica, Apogon sp., Bleekeria \\
& sp., Caranx sp. \\
& Selaroides leptolepis, Decapterus russelli, \\
& Nemipterus japonicus \\
& Rastrelliger kanagurta, Upeneus supravittatus, \\
& U. sulphureus \\
& Priacanthus sp., Secutor insidiator, \\
& S. ruconius, Otolithes ruber, Trichiurus lepturus \\
Decapoda & Acetes indicus, Fenneropenaeus indicus, \\
& Penaeus monodon, Metapenaeopsis stridulans, \\
& crablets, megalopa of crabs, zoea of crabs and \\
Stomatopoda & Lucifer \\
Octopoda & Squilla \\
Teuthida & Octopus \\
Veneroidea & Uroteuthis (Photololigo) duvaucelii, \\
& Loliolus (Nipponoloigo) uyii \\
& Clam shell \\
\hline & \\
&
\end{tabular}

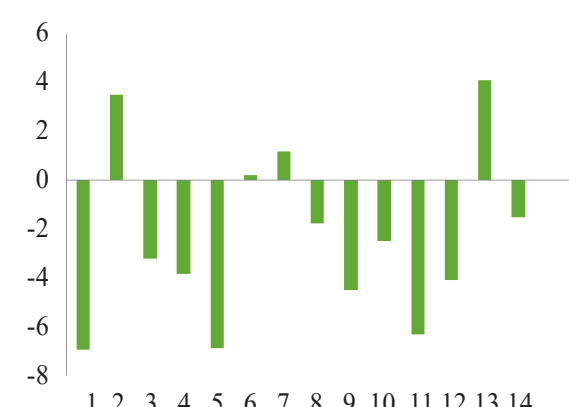

(a)

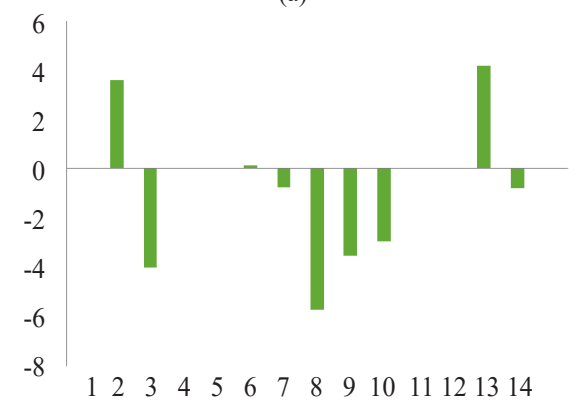

(c)
Table 4. Frequency of occurrence (O), Abundance (A, no.), Biomass (B, $\mathrm{g}$ ) and IRI \% of prey types of T. lepturus $(n=380)$

\begin{tabular}{lllll}
\hline Prey & O & A & B & IRI (\%) \\
\hline Anguilliformes & 1 & 1 & 0.1 & 0.001 \\
Clupeiformes & 107 & 113 & 617.1 & 33.737 \\
Gadiformes & 5 & 7 & 5.2 & 0.041 \\
Mugiliformes & 1 & 3 & 56 & 0.022 \\
Myctophiformes & 1 & 1 & 0.3 & 0.001 \\
Perciformes & 20 & 20 & 129.8 & 1.257 \\
Decapoda & 37 & 83 & 38.8 & 3.318 \\
Stomatopoda & 5 & 37 & 1.0 & 0.172 \\
Octopoda & 2 & 2 & 10.8 & 0.011 \\
Teuthida & 7 & 7 & 16.1 & 0.084 \\
Bivalvia & 1 & 2 & 0.002 & 0.002 \\
Fish larva & 4 & 4 & 1.4 & 0.017 \\
Semidigested fish & 191 & - & 421.1 & 61.115 \\
Digested matter & 14 & - & 8.5 & 0.221 \\
Total & 380 & 280 & 1306.2 & 100.00 \\
\hline
\end{tabular}

larger size, it tended to feed on relatively less varieties of prey types (only three prey types, which were all teleosts) than that of small fish (10 prey types).

Prey specific abundance (PSA)

The PSA (\%) was plotted against the frequency of occurrence ratio (O of prey i /O of all prey) (Fig. 5). The prey on the upper right side of the graph indicates

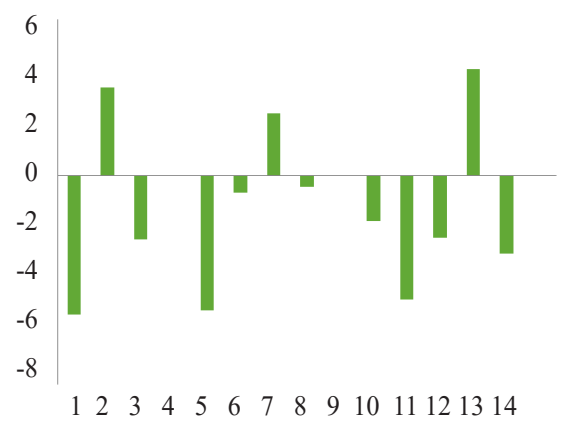

(b)

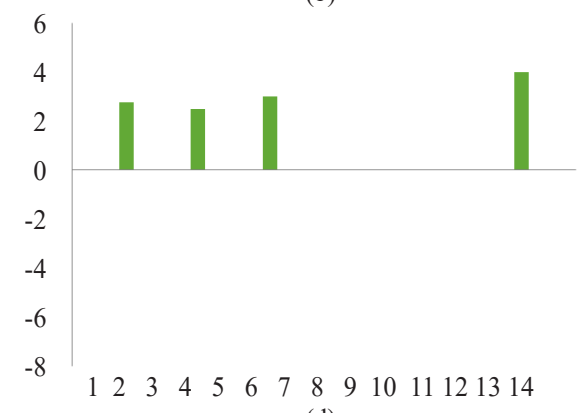

(d)

Fig. 4. Index of relative importance (Ln\% IRI) of prey groups of T. lepturus (a) in all ( $\mathrm{n}=380)$, (b) small, (c) medium and (d) large size groups. 1 - Anguilliformes; 2 - Clupeiformes; 3 - Gadiformes; 4 - Mugiliformes; 5 - Myctophiformes; 6 - Perciformes; 7 - Decapoda; 8 - Stomatopoda; 9 - Octopoda; 10 - Teuthida; 11 - Bivalvia; 12 - Fish larva; 13 - Semidigested fish; 14 - Digested matter 
specialised prey of the entire predator population; prey on the left upper side indicates specialised prey of a particular individual of the predator population and the prey on the left lower side indicates unimportant prey groups which are rarely eaten by some individuals of the predator population.

The plot showed that Clupeiformes was the specialised prey of T. lepturus population (Fig. 5a). A few individuals of the predator fed specifically on Decapoda, Gadiformes, Mugiliformes, Octopoda, Stomatopoda and Teuthida. The remaining 4 prey types were rare and unimportant as they clustered in the left lower side of the plot.

Clupeiformes remained the specialised prey of all size groups of the population (Fig. 5b and c). Decapods, Mugiliformes and Perciformes were the specialised prey of small and large size groups, respectively. In the large size group, Clupeiformes, Perciformes and Mugiliformes were the only prey types represented in the stomach (Fig. 5d), which is also evident from the IRI.

\section{Relationship between size of predator and prey}

To determine the relationship between the size of fish and prey, the stomachs containing single prey alone were considered. The prey length increased with increasing fish length upto $800 \mathrm{~mm}$ and there was no further increase in prey length in predators larger than $800 \mathrm{~mm}$ (Fig. 6a). Similar relationship (no increase in prey length for fish

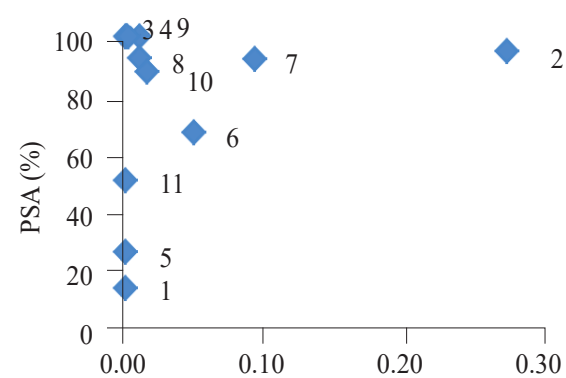

(a)

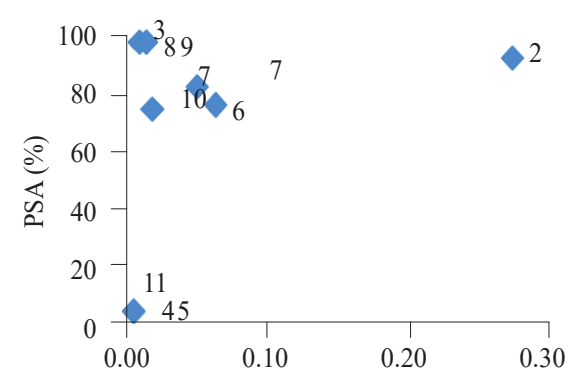

(c) above $800 \mathrm{~mm}$ length) was observed with reference to prey length and predator with full and gorged stomachs (Fig. 6b) as well as length of full and gorged stomach and prey length (Fig. 6c). In terms of weight also, the ribbonfish predated increasingly on large-sized prey until attaining $250 \mathrm{~g}$ body weight, but could not predate upon heavier prey with further increase in body weight (Fig. 6d). These relationships show that the ribbonfish has upper prey size limit in spite of increase in its body size as well as stomach length.

\section{Niche breadth}

The measure of niche breadth (B) and standardised measure of niche breadth (BA) for T. lepturus were 2.63 and 0.16 , respectively (Table 5). As the BA $(0.16)$ is nearer to 0 than to 1 , it indicates the specialised nature of feeding. This is because the fish was feeding predominantly on a single prey group, namely Clupeiformes. The niche breadth values were higher for small size group $(B=3.39$; $\mathrm{BA}=0.24$ ) indicating the relatively generalist nature of feeding by the small size group.

Trophic level (TrL)

T. lepturus had ingested prey types with a wide variety of feeding habits such as herbivores (oilsardine, Thryssa sp.), detritivores (shrimps), scavengers (decapods), filter feeders (bivalves), omnivores (Bregmaceros sp.) and carnivores (perches). The major diet of the predominant prey, namely, Clupeiformes were phytoplankton,

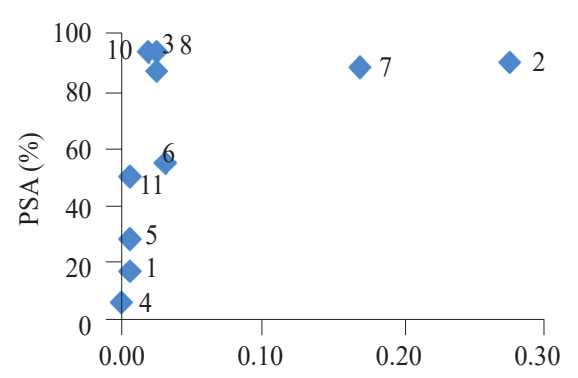

(b)

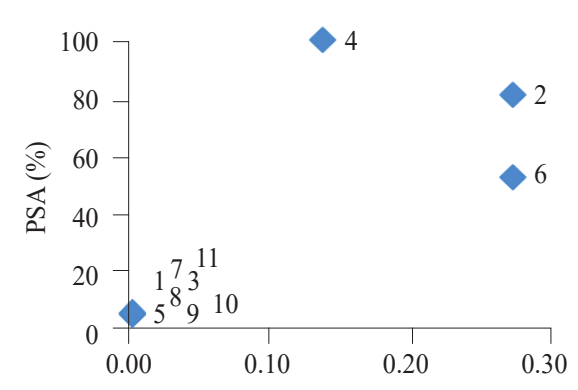

(d)

Fig. 5. Prey specific abundance (\%) in relation to frequency of occurrence (FO) of T. lepturus (a) in all (n=380), (b) small, (c) medium and (d) large size groups, 1 - Anguilliformes; 2 - Clupeiformes; 3 - Gadiformes; 4 - Mugiliformes; 5 - Myctophiformes; 6 - Perciformes; 7- Decapoda; 8 - Stomatopoda; 9 - Octopoda; 10 - Teuthida; 11- Bivalvia 


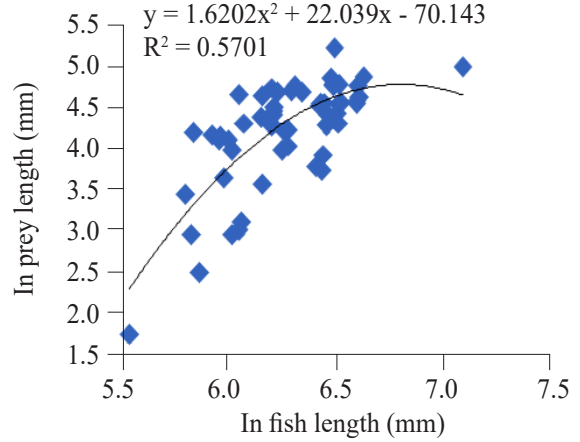

(a)

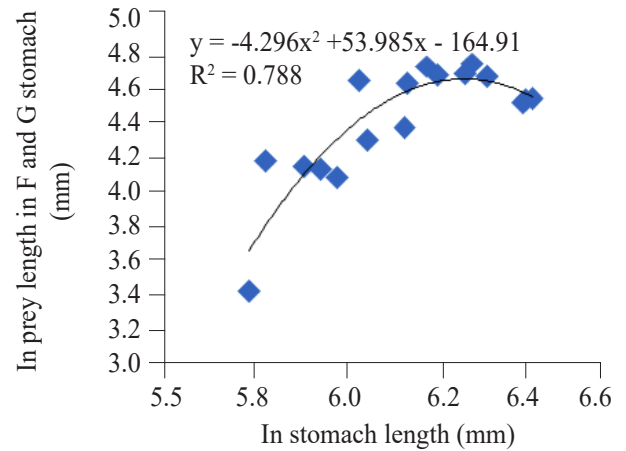

(c)

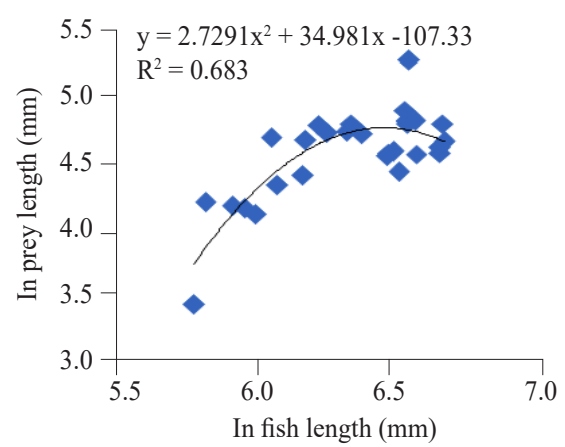

(b)

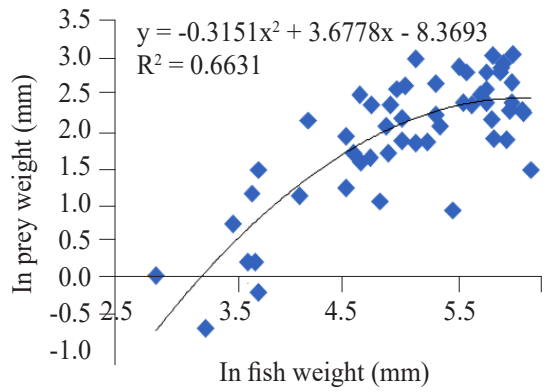

(d)

Fig. 6. Relationship between (a): Fish length and prey length $(n=58)$, b: Fish length and prey length in full and gorged stomachs $(n=29)$, c: Stomach length and prey length in full and gorged stomachs $(n=17)$, d: Fish weight and prey weight in full and gorged stomachs $(\mathrm{n}=54)$ of $T$. lepturus

Table 5. Levins measure of niche breadth (B) and standardised measure of niche breadth (BA) for T. lepturus

\begin{tabular}{lll}
\hline Size & B & BA \\
\hline Small & 3.39 & 0.24 \\
Medium & 2.04 & 0.10 \\
Large & 2.79 & 0.18 \\
All & 2.63 & 0.16 \\
\hline
\end{tabular}

copepods and algae. The trophic level of various prey types ranged from 2.0 (bivalves) to 3.7 (squids).

From the biomass and assigned trophic level of each prey type, the trophic level of T. lepturus was determined to range from 4.04 (large size group) to 4.21 (medium size group) with an overall TrL of 4.17 (Table 6). The estimated $\operatorname{TrL}$ value is close to the mean $\operatorname{TrL}$ value reported earlier for different species of ribbonfishes $(4.20 \pm 0.287)$ from Indian seas (Vivekanandan et al., 2009). The TrL of large size group was lower than the other two size groups, indicating ingestion of prey with relatively lower $\operatorname{TrL}$ with advancing age.

\section{Diet similarity}

Cluster analysis showed grouping of small and medium size groups at $62.9 \%$ similarity to which the
Table 6. Trophic level of T. lepturus

\begin{tabular}{ll}
\hline Size & Trophic level \\
\hline Small & 4.16 \\
Medium & 4.21 \\
Large & 4.04 \\
All & 4.17 \\
\hline
\end{tabular}

large group joined at $22.8 \%$. Hence the similarity in food preference between small and medium size groups was higher than that between small and large size groups.

\section{Discussion}

The largehead ribbonfish T. lepturus is primarily a midwater predator that consumes benthic, midwater and pelagic prey including fish, crustaceans and cephalopods, but primarily fish. Six of the 11 prey types were teleosts, two were crustaceans, two were cephalopods and one was a bivalve. Compared to other species of ribbonfishes, namely T. lepturus (=haumela) from south-east and southwest coasts of India (Prabhu, 1955) and Eupleurogrammus glossodon (=intermedius) off Mandapam (James, 1967), T. lepturus off Chennai had diverse and more prey types in the stomach. This may be due to availability of a large 
diversity of prey items off Chennai, or due to intensive prey analysis and better resolution of taxonomic identity of stomach samples in the present study, which has enabled recording more prey types.

The high species diversity of the Order Perciformes in the diet of T. lepturus was reflected in their representation by a large number of species/genera. Prey selectivity is based on availability and size of prey as well as energy/ protein content of prey. T. lepturus in the inner continental shelf of south-east Brazil selected prey that provided more energy per ingested biomass, so that the feeding events maximised the predator's caloric gain (Bittar et al., 2012).

About 40 to $50 \%$ of $T$. lepturus sampled in the present study had empty stomach in any day of sampling. Bakhoum (2007) reported up to $45 \%$ empty stomach for T. lepturus in the Egyptian Mediterranean coast. Wojciechowski (1972) found food in only 5\% of the stomachs examined in Mauritanis Shelf in the coast of north-west Africa and reported that the fish regurgitated when the trawlnet was hauled from the depth. However, this argument does not appear to hold good in the present study as the empty stomachs, when examined, were in a shrunken condition, suggesting that the fish did not ingest food for quite some time. High percentage of empty stomachs appear to be a characteristic of piscivorous fishes (Juanes and Conover, 1994). Occurrence of large number of individuals with empty stomach cannot be due to non-availability of preferred prey as the stomach of fishes occurring in the sample collected from the landings of a single haul was often in different states of fullness, from empty to gorged. This observation suggests that individuals within the population feed asynchronously, i.e. there is no particular time of feeding at the population level. In each stomach, all the food items available were found to be in any one stage of digestion, from non-digested to fully digested stage. However, the same prey item was found in different stages of digestion in different stomachs collected from T. lepturus sample in the same haul. For example, the prey Fenneropenaeus indicus was in advanced stage of digestion in the stomachs of $50 \%$ of a sample of T. lepturus collected from the same haul, in partially digested stage in the stomachs of $25 \%$ of the sample and in non-digested stage in the remaining $25 \%$ of the sample. The different stages of digestion of prey in the stomach of individuals collected from the same sample clearly shows that individuals in the population feed asynchronously. A similar feature has been reported for the threadfin bream Nemipterus japonicus off Veraval (Vivekanandan, 2001).

Another important feature was the condition of food in the stomach. Presence of large quantities of unidentifiable, semi-digested food in the stomach in almost all the samples (IRI was highest for semi-digested food) indicates that the fish disfigures the prey by piercing it using the fang-like teeth and/or takes long duration for digestion. The physical state of food passing through the gut varies with predator species and type of food. Chiou et al. (2006) and Bakhoum (2007) also reported that unidentifiable, semi-digested food was the most important component in the diet of T. lepturus in the Egyptian Mediterranean and coastal waters of south-western Taiwan, respectively. As the ribbonfish predates on large-sized prey, it is possible that digestion takes a long duration. It has been reported that predatory fishes evacuate their stomach in about $22 \mathrm{~h}$ (range: 6 - $48 \mathrm{~h}$ ), while herbivorous fishes evacuate their stomach in about $6 \mathrm{~h}$ (range: 3 - $10 \mathrm{~h}$ ) (Pandian and Vivekanandan, 1985).

The feeding behaviour of T. lepturus is aided by morphological adaptation of the fish to predation. The body is ribbon-like and elongated with maximum body depthtotal length ratio of 1: 17.1 , which is one of the highest among teleosts. This high ratio enables fast swimming to chase active prey. The longer lower jaw, large mouth gape, numerous, small, pointed needle-like canine teeth and 2 or 3 fang-like teeth in the upper jaw aid holding, piercing and killing large prey. The number of gill rakers are only 13 in each gill arch and are small (0.5-1.5 mm), hard and strong, preventing escape of the captured prey. Comparing the structural adaptations of four species of ribbonfishes, James (1967) concluded that the savalai ribbonfish Lepturacanthus savala has less number of, but the most powerful canine teeth without interspace, rudimentary gill rakers and lengthy jaws, which are suitable to predate very large prey compared to T. lepturus.

The study proves that carnivory does not require a long intestine and the RSL of T. lepturus is only 0.24 . It is reported that the RSL of carnivores ranges from 0.20 to 1.00 (Kapoor et al., 1975). The intestine of carnivorous fish, even though shorter compared to omnivorous and herbivorous fish, has evolved for processing highly digestible, nutrient-dense diet that is high in protein and low in carbohydrate (Buddington et al., 1997).

Changes in feeding strategy with increasing body size of T. lepturus were evident. Compared to small and medium size groups, the large individuals were characterised by occurrence of less number of empty stomach, significantly higher condition index, presence of only 3 of the potential 11 prey types in the stomach, narrow niche breadth, reduced trophic level and capacity to predate upon relatively larger prey, but in smaller numbers. With growth, the consumption of several benthic and midwater prey items, such as decapods, myctophids and bivalves decreased and predation upon larger prey such as Perciformes increased. However, as the large size group 
predated upon large quantities of Mugiliformes (45.1\% of total biomass consumed by the large size group), which has relatively low trophic level of 2.42, the trophic level of the large size group was lower than the other two smaller size groups. Nevertheless, the linear increase in mouth gape area with body size suggests that the fish develops the capacity to predate upon larger prey in proportion to its length as it grows. However, the capacity to hold the prey in the gut is limited beyond $800 \mathrm{~mm}$ length of the ribbonfish. Several researchers on ribbonfishes have reported dietary shift from zooplanktivore feeder at juvenile stage to voracious carnivore at adult stage (for example, Bakhoum, 2007; Bittar et al., 2012; Yan et al., 2012).

These diet changes were well represented in the IRI and PSA analysis. As the diet of all the three size groups was primarily from the same prey taxa, there is a possibility for potential dietary overlap between the size groups. However, competition between the three size groups is unlikely to be significant, because Perciformes and Mugiliformes were dominant only in the large size group and prey size linearly increased with the size of the predator. So, smaller ribbonfish predated on small-sized prey and the larger ones on large-sized prey of the same taxa.

While cannibalism was observed in only $1 \%$ of the total samples analysed, the observation assumes significance. Earlier studies (James, 1967; Thiagarajan et al., 1992; Bittar and Di Beneditto, 2009; Bittar et al., 2012; Yan et al., 2012) reported that the ribbonfish is a cannibal in all the size groups and seasons. Cannibalism is a widespread phenomenon in fishes that can have strong population and community effects (Juanes and Conover, 1994). High protein and energy contents associated with co-specifics, may make cannibalism energetically advantageous to the predator (Bittar et al., 2012). Cannibalism is also suggested as a strategy to transfer energy from smaller to larger individuals (Tanabe, 2001) and as one of the factors regulating population size (Lovrich and Sainte-Marie, 1997).

Predators with trophic level $>4$ and selective feeding are more vulnerable to fishing, changes in environment and decrease in availability of prey. These critical features of feeding-related vulnerability are evident in T. lepturus. Using a meta-analytic approach, Myers and Worm (2003) estimated that the large predatory fish biomass now is only $10 \%$ of pre-industrialised fishing. They also concluded that decline of large predators in coastal regions have extended throughout the global oceans. As predators are at the top of the food web, they exert top-down control on low trophic level organisms and decline in their biomass will have serious consequences on ecosystems.
Hence, findings on predatory fishes have ecosystemwide management implications. While the present study provides supporting information for management, it is important to regularly monitor and collect information on the fishery and abundance of ribbonfishes and other predatory fishes. Management of multispecies fisheries needs to focus more on the vulnerable predatory species, rather than on robust species.

\section{Acknowledgements}

We thank the Director, ICAR-Central Marine Fisheries Research Institute, Kochi for permission to undertake the work, Prof. Dr. S. Ajmal Khan and Dr. P. Murugesan, Centre of Advanced Studies in Marine Biology (Annamalai University), Parangipettai for help in analysis and interpretation of PRIMER data, Dr. P. Laxmilatha, Scientist-in-Charge, Madras Research Centre of ICAR-CMFRI for the support and facilities, Dr. K. Vinod, Principal Scientist for encouragement and Dr. Shoba Joe Kizhakudan, Principal Scientist for unconditional support. This paper is part of $\mathrm{Ph}$. D. Thesis submitted by the first author to the University of Madras, Chennai.

\section{References}

Alonso, K. M., Crespo, E. A., Pedraza, S. N., Garcy, A. and Coscarella, M. 2000. Food habits of the South American sea lion (Otaria flavescens) of Patagonia, Argentina. Fish. Bull., 98: 250-263.

Amundsen, P. A., Gabler, H. M. and Staldvik, F. I. 1996. A new approach to graphical analysis of feeding strategy from stomach contents data - modification of the Costello method. J. Fish Biol., 48: 607-614.

Bakhoum, S. A. 2007. Diet overlap of immigrant narrow-barred Spanish mackerel Scomberomorus commerson and the largehead hairtail ribbonfish Trichiurus lepturus in the Egyptian Mediterranean coast. Anim. Biodiver. Conserv., 30: $147-160$.

Bittar, V. T., Awabdi, D. R., Tonini, W. C. T., Vidal, M. V. and Di Beneditto, A. P. M. 2012. Feeding preference of adult females of ribbonfish Trichiurus lepturus through prey proximate-composition and caloric values. Neotrop. Ichthyol., 10: $197-203$.

Bittar, V. T. and Di Beneditto, A. P. M. 2009. Diet and potential feeding overlap between Trichiurus lepturus (Perciformes) and Pontoporia blainvillei (Cetacea) in northern Rio de Janeiro. Zoologia, 26: 374-378.

Buddington, R. K., Krogdahl, A. and Bakke-McKellep, A. M. 1997. The intestines of carnivorous fishes: structure and functions and the relations with diet. Acta Physiol. Scand., 161: 67-80.

Chiou, W., Chen, A., Wang, C. and Chen, C. 2006. Food and feeding habits of ribbonfish Trichiurus lepturus in coastal waters of south-western Taiwan. Fish. Sci., 72: 373-381. 
Clarke, K. R. and Gorley, R. N. 2006. PRIMER v6: User Manual/ tutorial. Plymouth Marine Laboratory, $91 \mathrm{pp}$.

Clements, K. D. and Choat, J. H. 1993 Influence of season, ontogeny and tide on the diet of the temperate marine herbivorous fish Odaxpullus (Odacidae). Mar. Biol., 117: 213-220.

Cortes, E. 1997. A critical review of methods of studying fish feeding based on analysis of stomach contents: application to elasmobranch fishes. Canadian J. Fish. Aquat. Sci., 54: 726-738.

Froese, R. and Pauly, D. 2000. FishBase 2000: Concepts, design and data sources. International Centre for Living Aquatic Resources Management, Los Baños, Laguna, Philippines, $344 \mathrm{pp}$.

Ghosh, S., Rao, M. V.H., Rohit, P., Rammohan, K. and Maheswarudu, G. 2014. Reproductive biology, trophodynamics and stock structure of ribbonfish Trichiurus lepturus from northern Arabian Sea and northern Bay of Bengal. Indian J. Geo-Mar. Sci., 43(5): 755-771.

Gomathy, S. 2013. Trophodynamics of selected fishes along Chennai coast. Ph. D. thesis, University of Madras, Chennai, 207 pp.

Holbrook, S. J. and Schmitt, R. J. 1984. Experimental analyses of patch selection by foraging black surfperch (Embiotoca jacksoni Agazzi). J. Exp. Mar. Biol. Ecol., 79: 39-64.

James, P. S. B. R. 1967. The ribbonfishes of the family Trichiuridae of India. Mar. Biol. Ass. India, Memoir I, 226 pp.

Juanes, F. and Conover, D. O. 1994. Rapid growth, high feeding rates and early piscivory in young-of-the-year bluefish (Pomatomus saltatrix). Canadian J. Fish. Aquat. Sci., 51: 1752-1761.

Kapoor, B. B., Smit, H. and Verighina, I. A. 1975. The alimentary canal and digestion in teleosts. Adv. Mar. Biol., 13: 109-239.

Levins, R. 1968. Evolution in changing environments: Some theoretical explorations. Princeton University Press, Princeton, $120 \mathrm{pp}$.

Lovrich, G. A. and Sainte-Marie, B. 1997. Cannibalism in the snow crab Chionoecetes opilio (Brachyura: Majidae) and its potential importance to recruitment. J. Exp. Mar. Biol. Ecol., 211: $225-245$.

McCormick, M. I. 1998. Ontogeny of diet shifts by a microcarnivorous fish, Cheilodactylus spectabilis: relationship between feeding mechanics, microhabitat selection and growth. Mar. Biol., 132: 9-20.

Myers, R. A. and Worm, B. 2003. Rapid worldwide depletion of predatory fish communities. Nature, 425: 280-283.

Pandian, T. J. and Vivekanandan, E. 1985. Energetics of feeding and digestion. In: Tytler, P. and Calow, P. (Eds.), Fish energetics: new perspectives. Croom Helm Publishers, London, p. 99-124.
Prabhu, M. S. 1955. Some aspects of the biology of the ribbonfish Trichiurus haumela (Forskal). Indian J. Fish., 2: 132-163.

Pillai, P. K. M. 1974. A note on the food and feeding habit of the ribbon fish, Trichiurus lepturus. Indian J. Fish., 21(2): 597-600.

Pillay, T. V. R. 1952. A critic method of the study of food of fishes. Zool. Soc. India, 4: 185-200.

Pinkas, L., Oliphant, M. S. and Iverson, I. L. K. 1971. Food habits of albacore, bluefin tuna and bonito in California waters. Calif. Fish Game Fish. Bull., 52: 105 pp.

Ribble, D. O. and Smith, M. H. 1983. Relative intestine length and feeding ecology of freshwater fishes. Growth, 47: 292-300.

Richardson, T. J., Potts, W. M., Santos, C. V. and Sauer, W. H. H. 2011. Ontogenetic dietary shift and morphological correlates for Diplodus capensis (Teleostei: Sparidae) in southern Angola. African Zool., 46: 280-287.

Snedecor, G. W. and Cochran, W. G. 1967. Statistical methods, $6^{\text {th }}$ edn. Oxford and IBH Publishing Co., New Delhi, 593 pp.

Tanabe, T. 2001. Feeding habits of skipjack tuna Katsuwonus pelamis and other tuna Thunnus spp. juveniles in the tropical western Pacific. Fish. Sci., 67: 563-570.

Thiagarajan, R., Lazarus, S., Sastry, Y. A., Khan, M. Z., Kasim, H. M. and Scariah, K. S. 1992. Stock assessment of the ribbonfish, Trichiurus lepturus Linnaeus from the Indian waters. Indian J. Fish., 39: 182-194.

Vivekanandan, E. 2001. Predatory diversity of two demersal finfish species in the trawling grounds off Veraval. Indian J. Fish., 48(2): 133-143.

Vivekanandan, E., Gomathy, S., Thirumilu, P., Meiyappan, M. M and Balakumar, S. K. 2009. Trophic level of fishes occurring along the Indian coast. J. Mar. Biol. Ass. India, 51: 44-51.

Vivekanandan, E., Srinath, M. and Kuriakose, S. 2005. Fishing the marine food web along the Indian coast. Fish. Res., 72(2-3): 241-252.

Ward-Campbell, B. M. S., Beamish, F. W. H. and Kongchaiya, C. 2005. Morphological characteristics in relation to diet in five coexisting Thai fish species. Fish. Soc. British Isles, 2005: 14 pp.

Wojciechowski, J. 1972. Observations on biology of cutlassfish Trichiurus lepturus L. (Trichiuridae) of Mauritania Shelf. Acta Ichthyol. Piscatoria, 2: 67-75.

Yan, Y., Chen, G., Hou, H. Lu and Lai, J. 2012. Feeding habits and ontogenetic diet shifts of hairtail, Trichiurus margatites in the Beibu Gulf of the South China Sea. Acta Ecol. Sinica, 32: 18-22. 